\title{
The Scope of Bipolar Disorders
}

\author{
Hagop S. Akiskal \\ International Mood Center \\ University of California at San Diego, USA
}

\section{DIAGNOSTIC AND PUBLIC HEALTH ASPECTS}

Recent advances in the epidemiology, psychopathology and pharmacotherapy of bipolar disorders have led to a greater recognition of this illness in all of its varieties (Akiskal et al., 2000). The lifetime risk for bipolar conditions is about $1 \%$ for the core (bipolar I) phenotype, making it at least equal in prevalence to schizophrenia. A higher percentage of acute psychiatric hospital admissions is now being assigned to the category of mania, and the recognition of clinically attenuated outpatient forms of the illness (soft bipolar spectrum) is increasing. The latter (bipolar II and beyond) is now estimated to be at least 4-5 times more prevalent than bipolar I (Angst et al., 2003; Hirschfeld et al., 2003; Judd and Akiskal, 2003).

Reasons for the current focus on the entire diagnosable range of bipolar conditions are several. Predominant among these is the tendency of diagnostic practice to follow the availability of effective treatment modalities (Lehmann, 1969). After the discovery of chlorpromazine, North American psychiatrists were tacitly encouraged to elicit subtle degrees of formal thought disorder from their patients so as to bring them the benefits of this new class of drugs. By the early 1970s, schizophrenia had become more or less synonymous with psychosis. With the advent of lithium carbonate treatment and its well-documented efficacy for bipolar disorders, this trend became reversed in favor of bipolar disorders. Beginning with DSM-III (American Psychiatric Association, 1980), the concept of schizophrenia has been largely restricted to a core group of deteriorating psychotic disorders, while mood disorders have been broadened to include even those with mood-incongruent psychotic features that may or may not coincide with affective episodes. This diagnostic approach reflects more than just therapeutic fashion; it is supported by familial aggregation, course and outcome (Akiskal, 2002). Available evidence indicates that mood disorders are often recurrent and, especially in bipolar conditions,

Bipolar Psychopharmacotherapy: Caring for the Patient Edited by Hagop S. Akiskal and Mauricio Tohen 
can lead to considerable impairment in developmental, conjugal and social spheres. The public health significance of bipolar disorder is summarized in Table 1.1. The most important of these is suicide, seen in as many as $20 \%$ of those who receive inadequate or no treatment, and must be considered a preventable complication (Khuri and Akiskal, 1983). It now appears that bipolar II may account for a disproportionately large portion of suicidal morbidity and mortality among all the affectively ill (Rihmer and Pestality, 1999), emphasizing the importance of early and accurate diagnosis.

At the "softest" end of the spectrum, milder degrees of bipolar disorder - subsumed under the rubrics of cyclothymic disorder (Akiskal etal., 1977) and bipolar disorder not otherwise specified (bipolar NOS) - are now categorized as mood disorders rather than being grouped with neurotic or personality disorders. Although these seemingly attenuated and "atypical" variants may not be easily distinguishable from nonaffective personality disorders, the clinician is advised to err on the side of affective diagnosis because of treatment implications.

External validating strategies - such as family history, course and inter-episodic temperamental features - are often necessary to confirm the diagnosis of the bipolar spectrum (Akiskal, 2003). The most established of bipolarity beyond classic mania and bipolar I is the bipolar II type, so-named originally by Dunner, Gershon and Goodwin (1976). Like diabetes type II, its onset is often insidious, but its ravages no less devastating than that of the psychotic forms of the illness. This is particularly true for cyclothymic depression, a variant of bipolar II we have termed "bipolar II-1/2" (Akiskal and Pinto, 1999). Arising from a cyclothymic temperament, it pursues an unstable course and is likely to be misdiagnosed as axis II cluster B. These patients represent the "dark side" of bipolarity (Akiskal, Hantouche and Allilaire, 2003; Hantouche, Angst and Akiskal, 2003).

The American Psychiatric Association (2000) Diagnostic Manual of Mental Disorders, even in its last edition (DSM-IV), does not recognize hypomanic or

Table 1.1: Public health aspects of bipolar disorder

- Lifelong cyclical illness

- $1-5 \%$ of population

- Peak onset $15-30$ years

- 5-10-year delay in correct diagnosis

- Frequent hospitalization

- Repeated hospitalization

- Repeated conjugal disruption: promiscuity

- Repeated job change/loss

- Financial disasters

- Alcohol/substance abuse

- $50 \%$ nonadherence to medication

- Increased cardiovascular mortality

- Suicide (highest within 10 years of illness onset) 
manic switches occurring during pharmacotherapy, electroconvulsive therapy, phototherapy and sleep deprivation as indicators of bipolar disorder. These patients are obviously not unipolar major depressive disorder (MDD), nor are they classified under bipolar not-otherwise specified (NOS). Therefore, this common clinical phenomenon is voted by the DSM Committee out of existence! Since at least 1983, there has been good evidence that such switching on antidepressants requires bipolar family history (Akiskal etal., 1983, 2000, 2003). They are best regarded as less penetrant forms of bipolar disorder (bipolar III). Diagnostic status of depressive states with mood swings in the setting of multiple drug abuse, particularly that of stimulants, is controversial, but we contend that many of these individuals belong to a provisional bipolar type III-1/2 (Akiskal and Pinto, 1999; Maremmani etal., 2003; Camacho and Akiskal, 2005). This is relevant in a book on advances in bipolar disorder, because many of these patients respond favorably to anticonvulsant mood stabilizers. Finally, I would like to mention bipolar type IV, which refers to individuals who develop depression later in life from a lifelong background of hyperthymic temperament (hypomanic traits without clear-cut episodes); their bipolar status might be inferred from familial bipolarity (Cassano et al., 1992).

In a French national study (Table 1.2), 65\% of all major depressions belonged to the bipolar spectrum, of which the most prevalent were the bipolar II and II-1/2 phenotypes (Akiskal etal., 2005b). These considerations are important because nearly all pharmacologic treatments covered in this book - certainly those approved by regulatory bodies - pertain to bipolar I. Thus, there is a wide gap between the psychopharmacology of bipolar disorder and the public health significance of the phenotypes observed in the community and the clinic.

Lithium was the first specific agent for bipolar disorder approved for clinical use. This was 35 years ago. Many other agents have been approved since then, almost all of them in the last decade. They are all covered in this book. Lithium medicalized psychiatry in bringing significant attention to the course of bipolar disorder. Its importance should not be overshadowed by these new developments. Many patients,

Table 1.2: Bipolar spectrum subtypes $(n=316)$ in the French EPIDEP study of major depression $(n=493)$ : validation by bipolar family history*

\begin{tabular}{lrr}
\hline & \multicolumn{1}{c}{$N$} & \multicolumn{1}{c}{$\%$} \\
\hline Bipolar I & 41 & 8.4 \\
Bipolar II & 61 & 12.4 \\
Bipolar II-1/2 & 164 & 33.5 \\
Bipolar III & 28 & 5.7 \\
Bipolar IV & 22 & 4.5 \\
Total & 316 & 64.5 \\
\hline
\end{tabular}

* Akiskal et al. (2005b) 
especially those in the "core" classic form of the illness, do respond to lithium. Its judicious use, often in combination with other agents in rational polypharmacy, requires intimate knowledge of its physiological and medical characteristics. Regrettably, young psychiatrists are not having adequate experience with this agent. A summary of the medical workup of patients in preparation of lithium use (Akiskal, 1999) is given in this chapter's appendix.

\section{PSYCHOLOGICAL AND SOCIAL ASPECTS}

The long-term, essentially life-long, nature of bipolar disorder and its vicissitudes dictate continuity of treatment and long-term caring. To solve practical problems in the patients' lives requires caring that goes beyond medications and psychotherapy, to include the family, significant others and the community.

Bipolar disorder continues to be poorly understood by both the public and doctors. More often than not, a bipolar child is classified as having conduct disorder or Attention Deficit Hyperactivity Disorder (ADHD) (Dilsaver, Henderson-Fuller and Akiskal, 2003). A teenager's suicide attempt is misattributed to problems of the heart, adolescent crisis or substance abuse; promiscuous behavior is blamed on childhood "sexual abuse." Bipolar patients from time to time describe their parents as "monsters" or "emotionally abusive," which some psychotherapists accept on blind faith without ever talking to the parents. Bipolar II patients are often diagnosed as unipolar and/or borderline personality (Akiskal, 2004), treated with antidepressants without mood stabilizers, resulting in tragic aggravation of the course of the illness (Akiskal and Mallya, 1987; Akiskal etal., 2005a). Excessive spending, squandering, of one's economic resources and pathological generosity may lead to financial ruin before bipolarity is considered.

Polls of members of the Depressive and Manic-Depressive Association in the U.S. have shown a latency of 10 years from the onset of symptoms until the correct diagnosis of bipolar disorder (Hirschfeld etal., 2003). Early diagnosis is critical because suicide in bipolar patients often occurs within this early period. The comfort, support, destigmatization, information and advocacy provided by such a conglomeration of patients, families and community leaders (many of whom are themselves bipolar) represents a novel approach in the rehabilitation of the bipolar patient into society. This is a humane and just cause.

Given that about $10 \%$ of patients with bipolar illness have creative and leadership achievements (Akiskal and Akiskal, 1988), sophisticated clinical management of bipolar illness can potentially safeguard the adaptive capacity and contributions that gifted bipolar people provide to society. Although psychotically ill (bipolar) patients are represented in the media as being creative, this is a destigmatization campaign at best and glamorizing madness at worst. Achievement and creativity are largely attributes of the softer spectrum represented in the attenuated temperamental expressions of bipolarity involving bipolar II (Akiskal and Akiskal, 1988, 2005). 
Spanning from temperament to psychosis, bipolarity is a fascinating yet tragic human condition. Mental health professionals who treat these individuals must use pharmacotherapy and psychosocial interventions compassionately, judiciously and rigorously - only rarely "aggressively." Severe bipolar illness is not just an ordinary illness to be medicated to "mediocrity." The temperament of these individuals deserves all our consideration and respect. While most psychotic bipolar patients are neither leaders nor creators, they are the reservoir of the genes, which in dilute form, might serve as the seeds of genius (Akiskal, 2000).

\section{APPENDIX: LABORATORY CONSIDERATIONS IN THE CLINICAL USE OF LITHIUM}

More than any other development, the introduction of lithium has emphasized the role of physicianship in psychiatry. The scientific literature and clinical wisdom on the therapeutic aspects of this salt have been well summarized in a monograph by Jefferson etal. (1983). The success of lithium treatment is dependent on the thoroughness of the initial workup, on dosage titration procedures and on appropriate monitoring throughout therapy.

The type of workup depends on the age of the patient and concurrent medical conditions (Table 1.3). In young (less than 40 years), physically healthy subjects, preparation for lithium therapy should include medical history (especially focused on neurologic, renal, cardiac, gastrointestinal, endocrine and cutaneous systems), physical examination and laboratory evaluation focusing on electrolytes and thyroid. In older patients or those with a history of cardiac disease, a baseline electrocardiogram (EKG) should be obtained, and an electroencephalogram (EEG) performed if epilepsy is suspected; if there is a history of renal disease, thorough evaluation of baseline kidney function is mandatory. Given rigorous indications for lithium, major medical illness and abnormalities in laboratory indices do not necessarily contraindicate its use; they do dictate, however, greater medical vigilance, including frequent determination of blood levels and use of lower doses.

Table 1.3: Recommended laboratory workup of patients considered for lithium therapy

\begin{tabular}{ll}
\hline Healthy $<40$ years & All others: consider \\
\hline Weight & EKG \\
CBC & EEG \\
T4/TSH & TRH test \\
FBS/serum electrolytes & 24-hour urine volume \\
Urinalysis & Urine concentration test \\
BUN/creatinine & Creatinine clearance \\
\hline
\end{tabular}


A short-term lithium trial in the controlled environment of a hospital is relatively easy to administer and is recommended for acutely manic, medically ill or elderly subjects. In outpatient practice, the physician must make sure that the patient and significant others understand the importance of adherence with periodic laboratory procedures and monitoring of side effects.

Lithium is rapidly and completely absorbed from the gastrointestinal tract and peaks in the serum in about 1.5-2.0 (standard preparation) or 4.0-4.5 hours (slow release preparation), depending on age. Its half-life varies from 24-36 hours; steady state is reached in about four days. Lithium is not protein bound and is excreted unchanged almost entirely through the kidneys. It can be safely combined with most classes of drugs except diuretics and nonsteroidal anti-inflammatory agents (other than aspirin), which tend to increase the serum lithium level.

Acutely manic and possibly bipolar depressive patients have a high tolerance for lithium and preferentially retain it during the first 10 days while excreting sodium; a regular diet is recommended. Postpubertal bipolar patients, who typically have excellent glomerular function, require higher doses to achieve the same level of equilibrium in the serum. The reverse is true in the geriatric age group. Elderly subjects with adequate glomerular function can benefit considerably from judicious lithium use. However, greater medical vigilance is required for this group; initial doses should be low (150-300 mg/day), with frequent clinical and laboratory monitoring to maintain blood levels in the lower range $(0.3-0.8 \mathrm{mEq} / \mathrm{L})$. Special attention must be paid to signs of sinus node dysfunction (bradycardia) or neurotoxicity; the latter is particularly likely in patients with concurrent neurologic disease or sedative and alcohol abuse.

In healthy subjects who achieve good episode prevention, quarterly serum levels (12 hours after the last dose) and serum creatinine are generally sufficient; thyroid indices must be obtained at least once a year. For elderly or medically compromised patients, laboratory tests should be repeated as dictated by the medical condition, with frequent serum lithium levels; the dosage should be kept at the lowest possible level compatible with prophylaxis.

\section{REFERENCES}

Akiskal HS. Mood (Affective) Disorders, in Berkhow R (ed.). Merck Manual of Diagnosis and Therapy, 17th ed. Rathaway, NJ, Merck Sharp and Dohme, 1999, pp. 1525-44.

Akiskal HS. Dysthymia, cyclothymia and related chronic subthreshold mood disorders. In Gelder M, Lopez-Ibor J, Andreasen N (eds). New Oxford Textbook of Psychiatry. London, Oxford University Press, 2000, pp. 736-749.

Akiskal HS. Classification, Diagnosis and boundaries of bipolar disorders. In Maj M, Akiskal HS, Lopez-Ibor JJ, Sartorius N (eds). Bipolar Disorder. London, John Wiley \& Sons, 2002, pp. 1-52.

Akiskal HS. Validating "hard" and "soft" phenotypes within the bipolar spectrum: Continuity or discontinuity? J. Affect. Disord. 2003; 73: 1-5. 
Akiskal HS. Demystifying borderline personality: Critique of the concept and unorthodox reflections on its natural kinship with the bipolar spectrum. Acta Psychiatr. Scand. 2004; 110: 401-407.

Akiskal HS, Akiskal KK. Re-assessing the prevalence of bipolar disorders: Clinical significance and artistic creativity. Psychiatrie et Psychobiologie. 1988; 3: 29s-36s.

Akiskal KK, Akiskal HS. The theoretical underpinnings of affective temperaments: Implications for evolutionary foundations of bipolarity and human nature. J. Affect. Disord. 2005; 85: 231-239.

Akiskal HS, Mallya G. Criteria for the "soft" bipolar spectrum: Treatment implications. Psychopharmacol. Bull. 1987; 23: 68-73.

Akiskal HS, Pinto O. The evolving bipolar spectrum: Prototypes I, II, III, IV. Psychiatr. Clin. North Am. 1999; 22: 517-534.

Akiskal HS, Hantouche EG, Allilaire J-F. Bipolar II with and without cyclothymic temperament: "dark" and "sunny" expressions of soft bipolarity. J. Affect. Disord. 2003; 73: 49-57.

Akiskal HS, Djenderedjian AH, Rosenthal RH, Khani MK. Cyclothymic disorder: Validating criteria for inclusion in the bipolar affective group. Am. J. Psychiatry. 1977; 134: 1227-1233.

Akiskal HS, Walker PW, Puzantian VR, King D, Rosenthal TL, Dranon M. Bipolar outcome in the course of depressive illness: Phenomenologic, familial, and pharmacologic predictors. J. Affect. Disord. 1983; 5: 115-128.

Akiskal HS, Bourgeois ML, Angst J, Post R, Moller HJ, Hirschfeld RMA. Re-evaluating the prevalence of and diagnostic composition within the broad clinical spectrum of bipolar disorders. J. Affect. Disord. 2000; 59 (Suppl 1): 5s-30s.

Akiskal HS, Hantouche EG, Allilaire JF, Sechter D, Bourgeois M, Azorin JM, ChatenêtDuchêne L, Lancrenon S. Validating antidepressant-associated hypomania (bipolar III): A systematic comparison with spontaneous hypomania (bipolar II). J. Affect. Disord. 2003; 73: 65-74.

Akiskal HS, Benazzi F, Perugi G, Rihmer Z. Agitated "unipolar" depression re-conceptualized as a depressive mixed state: Implications for the antidepressant-suicide controversy. J. Affect. Disord. 2005a; 85: 245-58.

Akiskal HS, Hantouche EG, Allilaire JF, Akiskal KK. Validating the bipolar spectrum: Overview of the phenomenology and relative prevalence of clinical subtypes in the French national EPIDEP study. J. Affect. Disord. 2005b, in press.

American Psychiatric Association. DSM-III. Diagnostic and Statistical Manual of Mental Disorders. Washington, DC: American Psychiatric Press, 1980.

American Psychiatric Association. DSM-IV. Diagnostic and Statistical Manual of Mental Disorders. Washington, DC: American Psychiatric Press, 2000.

Angst J, Gamma A, Benazzi F, Ajdacic V, Eich D, Rossler W. Toward a re-definition of subthreshold bipolarity: Epidemiology and proposed criteria for bipolar-II, minor bipolar disorders and hypomania. J. Affect. Disord. 2003; 73: 133-146.

Camacho A, Akiskal HS. Proposal for a bipolar-stimulant spectrum: Temperament, diagnostic validation and therapeutic outcomes with mood stabilizers. J. Affect. Disord. 2005; 85: 217-230.

Cassano GB, Akiskal HS, Savino M, Musetti L, Perugi G, Soriani A. Proposed subtypes of bipolar II and related disorders: With hypomanic episodes (or cyclothymia) and with hyperthymic temperament. J. Affect. Disord. 1992; 26: 127-140.

Dilsaver SC, Henderson-Fuller S, Akiskal HS. Occult mood disorders in 104 consecutively presenting children referred for the treatment of attention-deficit/hyperactivity 
disorder in a community mental health clinic. J. Clin. Psychiatry 2003; 64: $1170-1176$.

Dunner DL, Gershon ES, Goodwin FK. Heritable factors in the severity of affective illness. Biol. Psychiatry 1976; 11: 31-42.

Hantouche EG, Angst J, Akiskal HS. Factor Structure of hypomania: Interrelationships with cyclothymia and the soft bipolar spectrum. J. Affect. Disord. 2003; 73: 39-47.

Hirschfeld RM, Lewis L, Vornik LA. Perceptions and impact of bipolar disorder: How far have we really come? Results of the national depressive and manic-depressive association 2000 survey of individuals with bipolar disorder. J. Clin. Psychiatry 2003; 64: 161-74.

Hirschfeld RM, Holzer C, Calabrese JR, Weissman M, Reed M, Davies M, Frye MA, Keck P, McElroy S, Lewis L, Tierce J, Wagner KD, Hazard E. Validity of the mood disorder questionnaire: A general population study. Am. J. Psychiatry 2003; 160: 178-180.

Jefferson J, Greist JH, Ackerman DL, Carroll JA. Lithium Encyclopedia. Washington, DC: American Psychiatric Press, 1983.

Judd LL, Akiskal HS. The prevalence and disability of bipolar spectrum disorders in the U.S. population: Re-analysis of the ECA database taking into account subthreshold cases. J. Affect. Disord. 2003; 73: 123-131.

Khuri R, Akiskal HS. Suicide prevention: The necessity of treating contributory psychiatric disorders. Psychiatr. Clin. North Am. 1983; 6: 193-207.

Lehmann HE. The impact of the therapeutic revolution on nosology. In Doucet P, Laurin C (eds). Problematique de la psychose. New York, Excerpta Medica Foundation, 1969, pp. 136-153.

Maremmani I, Pacini M, Lubrano S, Lovrecic M, Perugi G. Dual diagnosis heroin addicts. The clinical and therapeutic aspects. Heroin Addict. Relat. Clin. Probl. 2003; 5: 7-98.

Rihmer Z, Pestality P. Bipolar II disorder and suicidal behavior. Psychiatr. Clin. North Am. 1999; 22: 667-73. 